\title{
Short communication: Use of a portable, automated, open- circuit gas quantification system and the sulfur hexafluoride tracer technique for measuring enteric methane emissions in Holstein cows fed ad libitum or restricted
}

\author{
C. D. Dorich, ${ }^{\star}$ R. K. Varner, * A. B. D. Pereira,† R. Martineau, $\ddagger$ K. J. Soder, $\S$ and A. F. Brito ${ }^{1}$ \\ *Institute for the Study of Earth, Oceans, and Space and Department of Earth Sciences, and \\ †Department of Biological Sciences, University of New Hampshire, Durham 03824 \\ ‡Dairy and Swine Research and Development Centre, Agriculture and Agri-Food Canada, Sherbrooke, Québec, Canada J1M 0C8 \\ §Pasture Systems and Watershed Management Research Unit, USDA-Agricultural Research Service, University Park, PA 16802
}

\begin{abstract}
The objective of this study was to measure enteric $\mathrm{CH}_{4}$ emissions using a new portable automated opencircuit gas quantification system (GQS) and the sulfur hexafluoride tracer technique $\left(\mathrm{SF}_{6}\right)$ in midlactation Holstein cows housed in a tiestall barn. Sixteen cows averaging $176 \pm 34 \mathrm{~d}$ in milk, $40.7 \pm 6.1 \mathrm{~kg}$ of milk yield, and $685 \pm 49 \mathrm{~kg}$ of body weight were randomly assigned to 1 out of 2 treatments according to a crossover design. Treatments were (1) ad libitum (adjusted daily to yield $10 \%$ orts) and (2) restricted feed intake [set to restrict feed by $10 \%$ of baseline dry matter intake (DMI)]. Each experimental period lasted 22 d, with 14 $\mathrm{d}$ for treatment adaptation and $8 \mathrm{~d}$ for data and sample collection. A common diet was fed to the cows as a total mixed ration and contained $40.4 \%$ corn silage, $11.2 \%$ grass-legume haylage, and $48.4 \%$ concentrate on a dry matter basis. Spot 5-min measurements using the GQS were taken twice daily with a 12 -h interval between sampling and sampling times advanced $2 \mathrm{~h}$ daily to account for diurnal variation in $\mathrm{CH}_{4}$ emissions. Canisters for the $\mathrm{SF}_{6}$ method were sampled twice daily before milking with 4 local background gas canisters inside the barn analyzed for background gas concentrations. Enteric $\mathrm{CH}_{4}$ emissions were not affected by treatments and averaged 472 and $458 \mathrm{~g} / \mathrm{d}$ (standard error of the mean $=18 \mathrm{~g} / \mathrm{d}$ ) for ad libitum and restricted intake treatments, respectively (data not shown). The GQS appears to be a reliable method because of the relatively low coefficients of variation (ranging from 14.1 to $22.4 \%$ ) for $\mathrm{CH}_{4}$ emissions and a moderate relationship (coefficient of determination $=0.42$ ) between $\mathrm{CH}_{4}$ emissions and DMI. The $\mathrm{SF}_{6}$ resulted in large
\end{abstract}

Received May 9, 2014.

Accepted December 23, 2014

${ }^{1}$ Corresponding author: andre.brito@unh.edu coefficients of variation (ranging from 16.0 to $111 \%$ ) for $\mathrm{CH}_{4}$ emissions and a poor relationship (coefficient of determination $=0.17$ ) between $\mathrm{CH}_{4}$ emissions and DMI, likely because of limited barn ventilation and high background gas concentration. Research with improved barn ventilation systems or outdoors is warranted to further assess the GQS and $\mathrm{SF}_{6}$ methodologies.

Key words: dairy cow, gas quantification system, methane, sulfur hexafluoride tracer technique

\section{Short Communication}

Several methodologies have been used to measure enteric $\mathrm{CH}_{4}$ emissions from dairy cattle, including calorimetric chambers (Blaxter and Clapperton, 1965; Hellwing et al., 2012), the sulfur hexafluoride tracer technique $\left(\mathbf{S F}_{6}\right.$; Johnson et al., 1994; Williams et al., 2011), open-path laser measurements (Laubach and Kelliher, 2005), continuous gas analyzer systems (Teye et al., 2009), head chambers (Kelly et al., 1994; Garnsworthy et al., 2012; Hegarty, 2013), and $\mathrm{CO}_{2}$ as a tracer (Madsen et al., 2010). All of these methods have some limitations and potential errors, which have been discussed in depth in the literature (Storm et al., 2012). An alternative method, a portable automated opencircuit gas quantification system (GQS; GreenFeed; C-Lock Inc., Rapid City, SD), was recently developed and it has now been used by researchers globally (Scott Zimmerman, C-Lock Inc., personal communication). The GQS allows for spot, automated measurements of $\mathrm{CH}_{4}$ and $\mathrm{CO}_{2}$ in real time with minimal disturbance of cow's natural behavior (Hegarty, 2013). The objective of the current study was to evaluate the enteric $\mathrm{CH}_{4}$ measurements obtained by the GQS and the $\mathrm{SF}_{6}$ tracer technique within a tiestall dairy barn. We hypothesized that short-term emissions using the GQS could be a precise (i.e., low CV) technique for capturing differences in $\mathrm{CH}_{4}$ emissions between treatments, whereas the $\mathrm{SF}_{6}$ tracer technique would lack accuracy under 
high background gas concentrations as a result of poor barn ventilation.

Use and care of animals was approved by the University of New Hampshire Institutional Animal Care Use Committee (no. 121203). The experiment was conducted at the University of New Hampshire Fairchild Dairy Teaching and Research Center located in Durham $\left(43.14^{\circ} \mathrm{N}, 70.95^{\circ} \mathrm{W}\right)$. A naturally ventilated tiestall barn with individual stalls $(1.8 \times 1.5 \mathrm{~m})$ covering both sides of the barn $(81 \mathrm{~m})$ equipped with a daily flushed manure gutter system was used. Ventilation was provided by windows that automatically opened to varying degrees depending on outside temperature. Windows were set to remain closed when the temperature was below $7.2^{\circ} \mathrm{C}$. The outside air temperature averaged -1.3 and $6.1^{\circ} \mathrm{C}$ during periods 1 and 2 , respectively, and was determined by hourly data from the National Climate Data Center weather station at the University of New Hampshire Kingman Farm, Durham $\left(43.13^{\circ} \mathrm{N}\right.$, $70.98^{\circ} \mathrm{W} ; 6 \mathrm{~km}$ away). Sixteen Holstein cows (12 multiparous and 4 primiparous) averaging $176 \pm 34$ DIM, $40.7 \pm 6.1 \mathrm{~kg}$ of milk yield, and $685 \pm 49 \mathrm{~kg}$ of BW at the start of the study were used. Baseline DMI (mean $=24.5 \pm 2.56 \mathrm{~kg} / \mathrm{d}$ ) was determined for 7 consecutive days before the start of the experiment. Cows were then blocked by DIM, parity, and DMI as a percentage of BW (mean $=3.94 \pm 0.35 \%$ ) and, within each block, randomly assigned to 1 out of 2 treatments according to a crossover design. The treatments were (1) ad libitum (AL) adjusted daily to yield $10 \%$ orts and (2) restricted feed intake (RFI) set to restrict feed by $10 \%$ of baseline DMI. Specifically, cows $(\mathrm{n}=16)$ in period 1 were split equally across treatments $(\mathrm{n}=8 /$ treatment $)$ and then switched to a new treatment (AL or RFI) in period 2. Each period lasted $22 \mathrm{~d}$ with $14 \mathrm{~d}$ for diet adaptation and $8 \mathrm{~d}$ for data and sample collection with both methods (i.e., GQS and $\mathrm{SF}_{6}$ ) used simultaneously to measure $\mathrm{CH}_{4}$ emissions from $\mathrm{AL}$ and RFI treatments. Cows were milked twice daily (0430 and 1600 h) with milk yield recorded throughout the duration of the study.

A TMR was fed to all cows and consisted (DM basis) of $40.4 \%$ corn silage, $11.2 \%$ grass-legume haylage, and $48.4 \%$ of a concentrate mix $[3.61 \%$ steam-flaked corn, $9.86 \%$ ground dry corn, $11.4 \%$ soybean meal, $7.33 \%$ citrus pulp, $0.71 \%$ molasses, $1.07 \%$ dry distillers grains with solubles, $3.50 \%$ canola meal, $2.93 \%$ soybean hulls, $0.18 \%$ urea, $3.30 \%$ minerals and vitamins, $1.59 \%$ ProvAAL Elite (AA supplement; Perdue Agribusiness Inc., Salisbury, MD), and $0.81 \%$ fat (BergaFat; Berg+Schmidt GmbH \& Co., Hamburg, Germany)]. Alfalfa pellets (Poulin Grain, Newport, VT; $16.9 \%$ CP, $56.0 \% \mathrm{NDF}$, and $35.0 \% \mathrm{ADF}$ ) used in the GQS comprised $2.11 \%$ (DM basis) of the TMR. The resulting
TMR averaged (DM basis): $16.8 \% \mathrm{CP}, 34.7 \% \mathrm{NDF}$, $24.3 \% \mathrm{ADF}$, and $19.2 \mathrm{MJ} / \mathrm{kg}$ of gross energy (Dairy One Laboratory, Ithaca, NY). Animals were fed twice a day (0500 and $1400 \mathrm{~h}$ ) with $40 \%$ of the total daily ration fed in the morning and the remaining $60 \%$ in the afternoon to account for the difference in feeding time intervals. Orts, if present, were removed and weighed daily before the afternoon feeding. Samples of TMR were collected daily, pooled by week, and stored at $-20^{\circ} \mathrm{C}$ until determination of $\mathrm{DM}\left(55^{\circ} \mathrm{C}\right.$ for $\left.48 \mathrm{~h}\right)$ in a forced-air oven (VWR Scientific, Radnor, PA).

The GQS operated by releasing $50 \mathrm{~g}$ of alfalfa pellets up to 5 times per feeding with a minimum of $45 \mathrm{~s}$ apart triggered by a radio frequency ear tag and the cow's head located inside the manger. This allowed $250 \mathrm{~g}$ of delivered alfalfa pellets per sampling and encouraged maintenance of the animals head inside the manger for feeding bouts lasting approximately $5 \mathrm{~min}$, which was needed for accurate breath sampling and near real-time analysis of $\mathrm{CH}_{4}$. Sampling times started at 0700 and $1900 \mathrm{~h}$ on $\mathrm{d} 1$ of the sampling period with the GQS moved sequentially from cow to cow with at least a 1-min interval between samplings for determination of background gas concentration. Sampling was advanced $2 \mathrm{~h}$ daily to account for diurnal variations in $\mathrm{CH}_{4}$ emissions, thus allowing for 14 measurements per cow per period. Cows were trained with the GQS during the 10 d before the beginning of the study. The $\mathrm{CH}_{4}$ sensor was calibrated weekly by purging sensors of any gas using purified $\mathrm{N}$ followed by a $1,000 \mathrm{mg} / \mathrm{kg}$ standard of $\mathrm{CH}_{4}$. At the beginning of each experimental period, the air flux sensor was calibrated using a 90-g prefilled $\mathrm{CO}_{2}$ cylinder (KEE Action Sports LLC, Sewell, NJ). Further details about sensors calibration, GQS operation, $\mathrm{CH}_{4}$ calculations, and data upload can be found on the manufacturer website (www.c-lockinc.com) and Hegarty (2013).

The $\mathrm{SF}_{6}$ technique originally described by Johnson et al. (1994) was used with the following adaptations. The permeation tubes were built from small $(11 \mathrm{~mm}$ o.d. $\times$ $32 \mathrm{~mm}$ ) brass permeation rods bored in the center with a 25.4-mm deep $\times 4.80 \mathrm{~mm}$ i.d. wide hole and loaded with 800 to $900 \mathrm{mg}$ of $\mathrm{SF}_{6}$ by direct syringe injection. The permeation tubes were capped and tightened with a 0.38-mm-thick polytetrafluoroethylene Teflon disc (McMaster Carr, Elmhurst, IL), a 2- $\mu \mathrm{m}$-pore stainless steel frit (Sigma-Aldrich, St. Louis, MO), and a 6.35-mm nut (Swagelok Inc., Solon, OH). Tubes were weighed immediately after filling and permeation release rates were determined by weighing tubes stored in a Daisy incubator (Ankom Technology, Macedon, NY; set to $39^{\circ} \mathrm{C}$ ) twice weekly. Permeation tubes were weighed for a minimum of 6 wk to determine $\mathrm{SF}_{6}$ permeation rates with rates varying from 1.13 to $4.97 \mathrm{mg} / \mathrm{d}$ (mean = 
$\left.2.67 \pm 1.09 \mathrm{mg} / \mathrm{d} ; \mathrm{R}^{2}>0.99\right)$. Permeation tubes were orally dosed to cows 2 wk before sample collection and were distributed evenly between the 2 treatments based on DMI as percentage of BW resulting in average permeation rates of 2.88 and $2.91 \mathrm{mg} / \mathrm{d}$ for $\mathrm{AL}$ and $\mathrm{RFI}$ treatments, respectively.

Canisters (10.2-cm diameter polyvinyl chloride, 17.8 cm length, $1 \mathrm{~L}$ ) capped (10.2-cm polyvinyl chloride end caps) and adapted with a $1.10-\mathrm{cm}$ hole fitted with a ball shutoff valve were connected to the sampling apparatus built into a halter as previously described (Makkar and Vercoe, 2007). Halters allowed for positioning of filters and capillary tubing $(1.59 \mathrm{~mm}$ o.d. and $0.13 \mathrm{~mm}$ i.d.; Sigma-Aldrich) that sampled directly above the cows' nostrils and were designed to sample continuously and evenly for $12 \mathrm{~h}$ based on capillary tubing length and canister vacuum. Canisters were collected from cows twice daily immediately before milking times (0430 and $1600 \mathrm{~h}$ ) and replaced with a new flushed and evacuated canister after cows returned from the milking parlor approximately $1 \mathrm{~h}$ later. Canisters were diluted (Makkar and Vercoe, 2007) with an ultra-high purity $\mathrm{N}$ gas (Specair; Maine Oxy, Southborough, MA) for sample collection and analysis. Gas samples were removed from the canisters and injected into pre-evacuated 10$\mathrm{mL}$ vials with septa (Labco, Houston, TX) and stored until analysis using a Shimadzu GC-8A (Shimadzu, Kyoto, Japan) equipped with flame ionization detection and electron capture detection for $\mathrm{CH}_{4}$ and $\mathrm{SF}_{6}$, respectively.

Four local background gas (LBG) canisters were placed at 4 different locations among the cows to minimize spatial effects observed in tracer studies (Williams et al., 2011; Lassey, 2013). Based on locations of the cows and their respective permeation rates, 2 LBG canisters were closer to cows orally dosed with higher $\mathrm{SF}_{6}$ permeation rates and 2 canisters were closer to the cows with lower $\mathrm{SF}_{6}$ permeation rates. Due to the large and variable background concentrations measured within the barn, a data filter was applied to remove emission values that were unrealistic. Methane emissions were filtered within a range of 150 to $800 \mathrm{~g} / \mathrm{d}$, which was established based on values reported in the literature (Grainger et al., 2007; Hollmann et al., 2012; Muñoz et al., 2012). The background gas concentration used for the calculation of emissions from each cow was based on a selection procedure that consisted of (1) using the background gas concentrations from the closest LBG to the cow, (2) using the LBG average concentrations for $\mathrm{SF}_{6}$ and $\mathrm{CH}_{4}$ for the respective collection period of the cow sample, or (3) if the $\mathrm{SF}_{6}$ sample had a higher $\mathrm{SF}_{6}$ concentration than the LBG average concentration used in step 2, individual LBG canisters were used. Our rationale for using this step-based protocol was that LBG concentrations need to be sampled near the cow to accurately calculate $\mathrm{CH}_{4}$ emissions (Lassey, 2013). If an emission could not be calculated based on the closest LBG, it is conceivable that this specific LBG poorly represented the background gas concentration for that cow, or that there was a sampling issue. Sampling apparatus broken by cows or blockage of tubing from feed prevented sampling from all canisters resulting in 82 (period 1) and $88 \%$ (period 2) of canisters being sampled, which is in line with previous research (Grainger et al., 2007). Calculations of enteric $\mathrm{CH}_{4}$ emissions were done according to Johnson et al. (1994).

Data were analyzed using the MIXED procedure of SAS (version 9.3; SAS Institute Inc., Cary, NC) for a crossover design with repeated measures over time using a statistical model similar to that reported by Brito et al. (2014). Neither day nor day $\times$ treatment interaction was significant and both were removed from the final model. Results are reported as LSM with significance declared at $P \leq 0.05$. A minimum of 5 measurements per cow per period were required for inclusion of a cow into period emission averages. One $\mathrm{CH}_{4}$ and $2 \mathrm{SF}_{6}$ outliers were removed from background concentrations during period 1 . One cow refused to use the GQS during both periods.

Intake of DM averaged 23.8 and $22.4 \mathrm{~kg} / \mathrm{d}(\mathrm{SEM}=$ $0.68 \mathrm{~kg} / \mathrm{d})$ and was highest $(P<0.01)$ for the AL treatment (data not shown). Conversely, $\mathrm{CH}_{4}$ emissions, using period averages, did not differ significantly between treatments and averaged 472 and $458 \mathrm{~g} / \mathrm{d}(\mathrm{SEM}=18$ $\mathrm{g} / \mathrm{d}$ ) for AL and RFI treatments, respectively (data not shown). This lack of difference in $\mathrm{CH}_{4}$ emissions may be explained by the relatively modest difference $(-1.4$ $\mathrm{kg} / \mathrm{d}$ ) in DMI between treatments. The CV observed for $\mathrm{CH}_{4}$ measurements were up to 5-fold greater for the $\mathrm{SF}_{6}$ method compared with the GQS (Table 1). Large variability in emissions has been reported in enteric $\mathrm{CH}_{4}$ studies partially due to inter- and intra-animal variability, but in general a higher variability has been observed in studies using $\mathrm{SF}_{6}$ (Pinares-Patino et al., 2011; Storm et al., 2012). Average emissions based on all individual measurements were $468 \pm 105$ and 467 $\pm 519 \mathrm{~g} / \mathrm{d}$ for GQS and $\mathrm{SF}_{6}$, respectively (Table 1). However, when values outside the range of 150 to 800 $\mathrm{g} / \mathrm{d}$ of $\mathrm{CH}_{4}$ were removed from the data set, the average per cow per period $\mathrm{CH}_{4}$ emissions decreased from $464 \pm 213$ to $405 \pm 65 \mathrm{~g} / \mathrm{d}$ for the SF6 technique but did not change for the GQS method (Table 1). It is important to note that data-filtered $\mathrm{CH}_{4}$ emissions per cow per period were within the range of values reported elsewhere (Aguerre et al., 2011; Hassanat et al., 2013; Hristov et al., 2013). 
Table 1. Description of data set used to assess $\mathrm{CH}_{4}$ emissions measured by the portable automated open-circuit gas quantification system (GQS) and the sulfur hexafluoride $\left(\mathrm{SF}_{6}\right)$ tracer technique

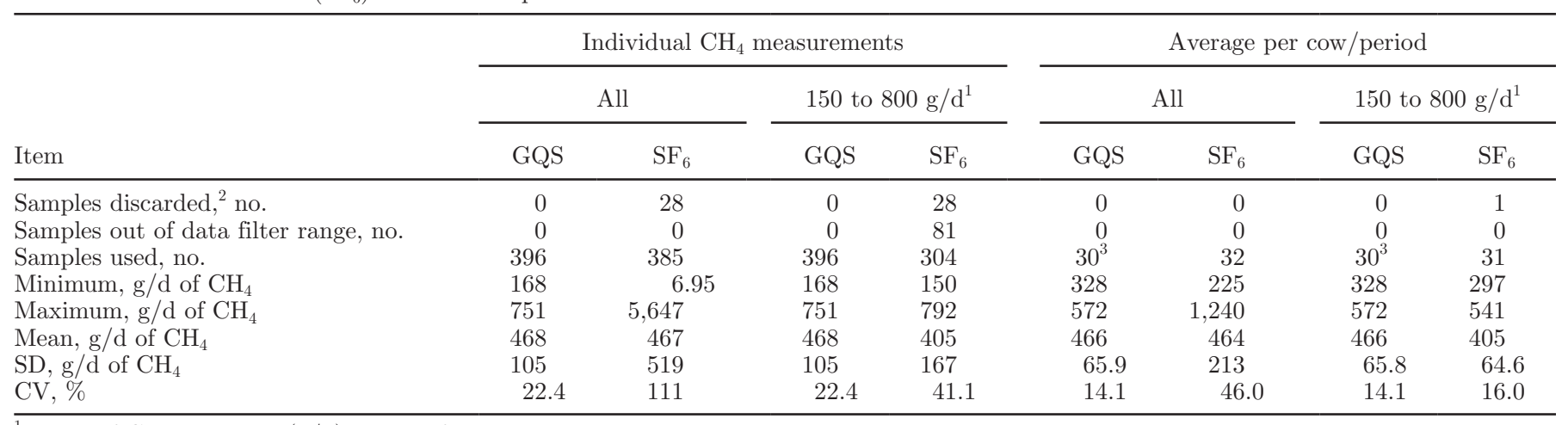

${ }^{1}$ Range of $\mathrm{CH}_{4}$ emissions (g/d) used to filter the data set.

${ }^{2}$ Twenty-eight negative $\mathrm{CH}_{4}$ measurements were discarded and 1 average/cow per period was discarded because only $3 \mathrm{CH}_{4}$ measurements were available to calculate the average.

${ }^{3}$ One cow refused to use the GQS during both periods.

Methane emissions were linearly related to DMI $(P$ $<0.01$; Figure 1$)$, with a better fit for the GQS $(\mathrm{n}=$ $\left.30 ; \mathrm{R}^{2}=0.42\right)$ compared with the $\mathrm{SF}_{6}$ technique ( $\mathrm{n}=$ $\left.31 ; \mathrm{R}^{2}=0.17\right)$. Based on the lower CV calculated from individual measurements and the stronger relationship between $\mathrm{CH}_{4}$ emissions and DMI, the GQS appears to be more reliable than the $\mathrm{SF}_{6}$ technique under the poor barn ventilation and high background gas concentration conditions of the current study.

Our data corroborate previous studies in which large variability in background gas concentrations were detected in experiments conducted with $\mathrm{SF}_{6}$ (Williams et al., 2011). Measured LBG values ranged from 21.3 to $77.6 \mu \mathrm{g} / \mathrm{kg}$ of $\mathrm{CH}_{4}$ (mean $=44.8 \pm 10.1 \mu \mathrm{g} / \mathrm{kg}$ ), whereas those of $\mathrm{SF}_{6}$ ranged from 24.9 to $390 \mathrm{ng} / \mathrm{kg}$ (mean $=120.5 \pm 60.1 \mathrm{ng} / \mathrm{kg}$ ) during the 2 periods (data not shown). The barn windows remained closed most of the time during the study due to low outdoor temperatures, resulting in poor ventilation. Although the presence of 80 lactating dairy cows and a manure gutter with daily flushing also contributed to background gas concentrations higher than previously reported in $\mathrm{SF}_{6}$ studies (Vlaming et al., 2007), current background concentrations were consistent with those reported for a naturally ventilated barn (Ngwabie et al., 2011). It is noteworthy, however, that $\mathrm{CH}_{4}$ emissions are not expected to be affected by recycling of self-inhaled gases (Lassey, 2013). This indicates that the large background variability between samplings and LBG canisters is likely more concerning than a high background gas concentration itself. It is well known that the precision of the $\mathrm{SF}_{6}$ tracer technique is partially dependent on maintaining low background concentrations and variability, which allows differences in $\mathrm{CH}_{4}$ emissions to be detected (Williams et al., 2011; Lassey, 2013). Permeation rates ranging from 1.13 to $4.97 \mathrm{mg} / \mathrm{d}_{\text {of }} \mathrm{SF}_{6}$ (mean $=2.67$ $\pm 1.09 \mathrm{mg} / \mathrm{d}$ ) likely contributed to the large variation in our data set, as background gas concentrations can be influenced by neighboring cows with different permeation rates (Lassey, 2013). Whereas the GQS measures a background concentration before sampling the animal, the effects of ventilation and background gas concentration have not yet been examined to the best of our knowledge.

One of the main benefits of the $\mathrm{SF}_{6}$ method is the ability to sample a large number of animals particularly in outdoor settings (Storm et al., 2012). The GQS was also designed with the intent of sampling a large number of animals (Hegarty, 2013). However, the GQS sampling protocol is still under development and will be optimized by emerging research. Even though the GQS sampling protocol used herein aimed to account for diurnal variation in $\mathrm{CH}_{4}$ emissions, the low sampling frequency (i.e., twice daily) may not have fully captured the daily fluctuation in $\mathrm{CH}_{4}$ emissions. In addition to low sampling frequency, $\mathrm{CH}_{4}$ emissions may be biased by sampling collection time as $\mathrm{CH}_{4}$ emissions are generally highest after feeding and during rumination bouts (Storm et al., 2012; Hegarty, 2013). However, this potential bias was likely minor in our study, as sampling was scheduled to accommodate a diurnal pattern rather than random animal visits (Hegarty, 2013). An additional constraint of the GQS is the requirement for delivering a bait to attract cows to the manger and keep animals for 3 to 6 min while $\mathrm{CH}_{4}$ emissions from eructated gas are measured (Hegarty, 2013). This procedure may require up to $1 \mathrm{~kg}$ of feed (usually pelleted feed) to be delivered over 4 to 6 visits daily, which increases total dietary energy intake potentially affecting $\mathrm{CH}_{4}$ emissions by the measurement process itself (Hegarty, 


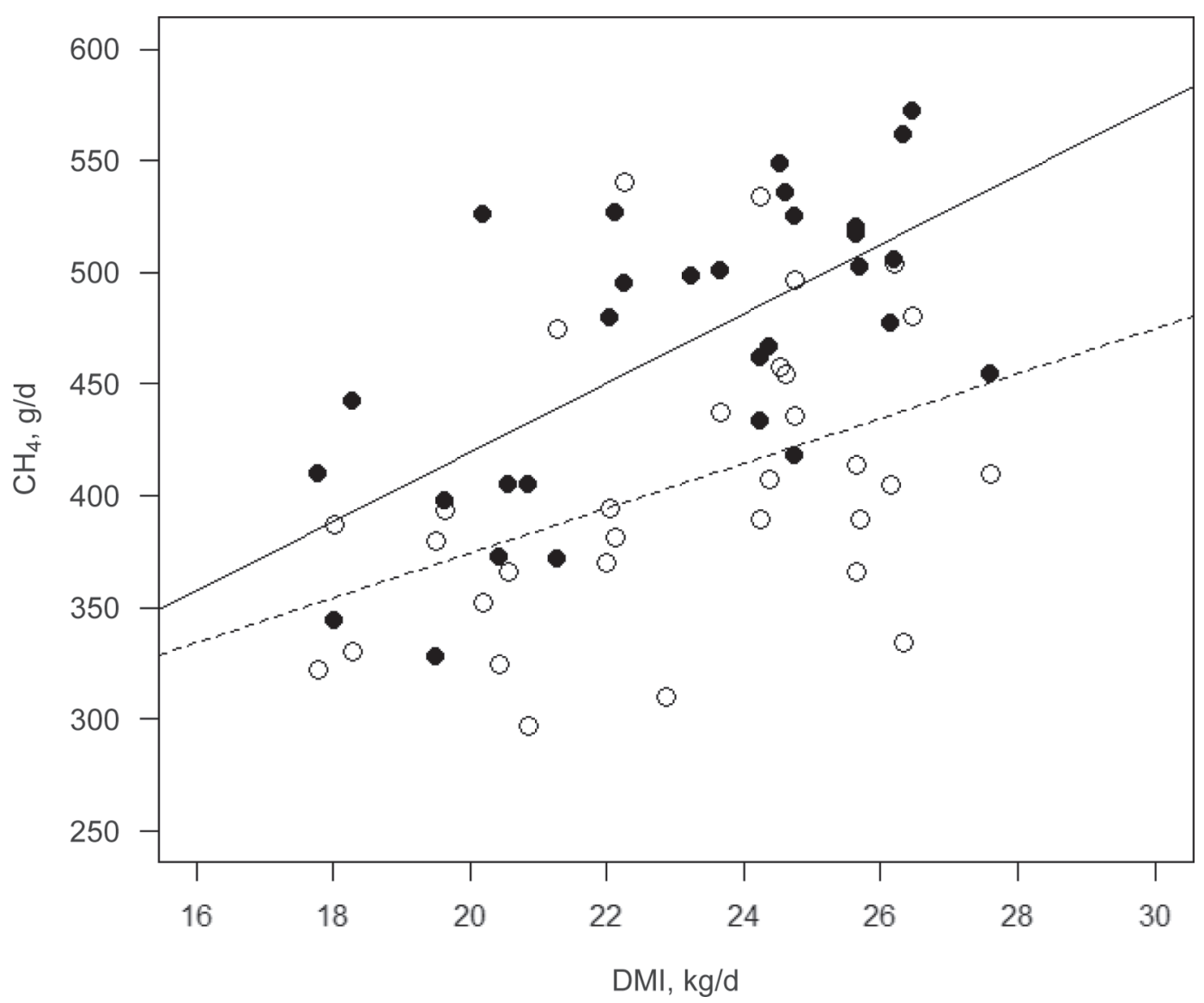

Figure 1. Relationships between $\mathrm{CH}_{4}$ emissions and DMI for the portable automated open-circuit gas quantification system $\left(\mathrm{GQS}\right.$; $\mathrm{R}^{2}=$ $0.42, P<0.01$; closed circles and continuous line) and the sulfur hexafluoride $\left(\mathrm{SF}_{6}\right)$ tracer technique $\left(\mathrm{R}^{2}=0.17, P=0.02 ;\right.$ open circles and dashed line).

2013). Animals in the current study consumed (as fed basis) approximately $500 \mathrm{~g}$ of alfalfa pellets daily and the potential interference on $\mathrm{CH}_{4}$ emissions was likely minor and distributed across both treatments.

Overall, data from the GQS (i.e., relatively low CV and significant relationship between DMI and $\mathrm{CH}_{4}$ emissions with a moderate $\mathrm{R}^{2}$ ) indicate that this methodology can be used to obtain reliable enteric $\mathrm{CH}_{4}$ emissions data with minimal animal disturbance. Even though the $\mathrm{SF}_{6}$ tracer technique showed high variability and a poor relationship between DMI and $\mathrm{CH}_{4}$ emissions, the high concentration of background gases combined with poor barn ventilation were likely more prejudicial to the $\mathrm{SF}_{6}$ than the GQS methodology. Research with improved barn ventilation systems or outdoors is warranted to further assess these 2 methodologies. Future studies should also report a detailed description of the methodology and data management protocol used to enable unbiased comparisons of enteric $\mathrm{CH}_{4}$ emissions across sites and experiments.

\section{ACKNOWLEDGMENTS}

Partial funding was provided by the New Hampshire Agricultural Experiment Station (Durham). This is Scientific Contribution Number 2591. Research was also supported by USDA-National Institute of Food and Agriculture (Washington, DC) award (\#2010-5110621834) and Hatch Multistate NC-1042 (Project Number NH00616-R; Project Accession Number 1001855). The authors also thank University of New Hampshire (Durham campus) students Kelly S. O'Connor, Alexandra M. Catalano, Alex Kratzert, and Apryl Perry as well as Milena Lima (Universidade Estadual de Santa Cruz, Ilhéus, Bahia, Brazil) and Daniel Abreu (Universidade Federal de Viçosa, Viçosa, Minas Gerais, Brazil) for their help in collecting and analyzing samples. Gratitude is extended to Melissa Rubano and John Everhart at USDA-Agricultural Research Service, and Pat and Scott Zimmerman with C-Lock Inc. (Rapid City, SD) for their technical support. 


\section{REFERENCES}

Aguerre, M. J., M. A. Wattiaux, J. M. Powell, G. A. Broderick, and C. Arndt. 2011. Effect of forage-to concentrate ratio in dairy cow diets on emission of methane, carbon dioxide, and ammonia, lactation performance, and manure excretion. J. Dairy Sci. 94:3081-3093.

Blaxter, K. L., and J. L. Clapperton. 1965. Prediction of the amount of methane produced by ruminants. Br. J. Nutr. 19:511-522.

Brito, A. F., G. F. Tremblay, A. Bertrand, Y. Castonguay, G. Bélanger, R. Michaud, C. Lafrenière, R. Martineau, and R. Berthiaume. 2014. Alfalfa baleage with increased concentration of nonstructural carbohydrates supplemented with a corn-based concentrate did not improve production and nitrogen utilization in early lactation dairy cows. J. Dairy Sci. 97:6970-6990.

Garnsworthy, P. C., J. Craigon, J. H. Hernandez-Medrano, and N. Saunders. 2012. On-farm methane measurements during milking correlate with total methane production by individual dairy cows. J. Dairy Sci. 95:3166-3180.

Grainger, C., T. Clarke, S. M. McGinn, M. J. Auldist, K. A. Beauchemin, M. C. Hannah, G. C. Waghorn, H. Clark, and R. J. Eckard. 2007. Methane emissions from dairy cows measured using the sulfur hexafluoride $\left(\mathrm{SF}_{6}\right)$ tracer and chamber techniques. J. Dairy Sci. 90:2755-2766.

Hassanat, F., R. Gervais, C. Julien, D. I. Massé, A. Lettat, P. Y. Chouinard, H. V. Petit, and C. Benchaar. 2013. Replacing alfalfa silage with corn silage in dairy cow diets: Effects on enteric methane production, ruminal fermentation, digestion, $\mathrm{N}$ balance, and milk production. J. Dairy Sci. 96:4553-4567.

Hegarty, R. S. 2013. Applicability of short-term emission measurements for on-farm quantification of enteric methane. Animal 7:401-408.

Hellwing, A. L. F., P. Lund, M. R. Weisbjerg, M. Brask, and T. Hvelplund. 2012. Technical note: Test of a low-cost and animal-friendly system for measuring methane emissions from dairy cows. J. Dairy Sci. 95:6077-6085.

Hollmann, M., W. J. Powers, A. C. Fogiel, J. S. Liesman, N. M. Bello, and D. K. Beede. 2012. Enteric methane emissions and lactational performance of Holstein cows fed different concentrations of coconut oil. J. Dairy Sci. 95:2602-2615.

Hristov, A. N., C. Lee, T. Cassidy, K. Heyler, J. A. Tekippe, G. A. Varga, B. Corl, and R. C. Brandt. 2013. Effect of Origanum vulgare L. leaves on rumen fermentation, production, and milk fatty acid composition in lactating dairy cows. J. Dairy Sci. 96:1189-1202.

Johnson, K., M. Huyler, H. Westberg, B. Lamb, and P. Zimmerman. 1994. Measurement of methane emissions from ruminant livestock using a $\mathrm{SF}_{6}$ tracer technique. Environ. Sci. Technol. 28:359-362.

Kelly, J. M., B. Kerrigan, L. P. Milligan, and B. W. McBride. 1994. Development of a mobile, open-circuit indirect calorimetry system. Can. J. Anim. Sci. 74:65-71.
Lassey, K. R. 2013. On the importance of background sampling in applications of the $\mathrm{SF}_{6}$ tracer technique to determine ruminant methane emissions. Anim. Feed Sci. Technol. 180:115-120.

Laubach, J., and F. M. Kelliher. 2005. Methane emissions from dairy cows: Comparing open path laser measurements to profile-based techniques. Agric. For. Meteorol. 135:340-345.

Madsen, J., B. S. Bjerg, T. Hvelplund, M. R. Weisbjerg, and P. Lund. 2010. Methane and carbon dioxide ratio in excreted air for quantification of the methane production from ruminants. Livest. Sci. 129:223-227.

Makkar, H. P. S., and P. E. Vercoe. 2007. Measuring methane production from ruminants. Chapter 3 in The $\mathrm{SF}_{6}$ Tracer Technique: Methane Measurement from Ruminants. K. A. Johnson, H. H. Westberg, J.J. Michal, and M. W. Cossalman, ed. IAEA. Springer, Dordecht, the Netherlands.

Muñoz, C., T. Yan, D. A. Wills, S. Murray, and W. Gordon. 2012. Comparison of the sulfur hexafluoride tracer and respiration chamber techniques for estimating methane emissions and correction for rectum methane output from dairy cows. J. Dairy Sci. 95:3139-3148.

Ngwabie, N. M., K.-H. Jeppsson, G. Gustafsson, and S. Nimmermark. 2011. Effects of animal activity and air temperature on methane and ammonia emissions from a naturally ventilated building for dairy cows. Atmos. Environ. 45:6760-6768.

Pinares-Patino, C. S., K. R. Lassey, R. J. Martin, G. Molano, M. Fernandez, S. Maclean, E. Sandoval, D. Luo, and H. Clark. 2011. Assessment of the sulphur hexafluoride $\left(\mathrm{SF}_{6}\right)$ tracer technique using respiration chambers for estimation of methane emissions from sheep. Anim. Feed Sci. Technol. 166-167:201-209.

Storm, I. M. L. D., A. L. F. Hellwing, N. I. Nielsen, and J. Madsen. 2012. Methods for measuring and estimating methane emissions from ruminants. Animal 2:160-183.

Teye, F. K., E. Alkkiomaki, A. Simojoki, M. Pastell, and J. Ahokas. 2009. Instrumentation, measurement and performance of three air quality measurement systems for dairy buildings. Appl. Eng. Agric. 25:247-256.

Vlaming, J. P., I. M. Brookes, S. O. Hoskin, C. S. Pinares-Patino, and H. Clark. 2007. The possible influence of intra-ruminal sulphur hexafluoride release rates on calculated methane emissions from cattle. J. Anim. Sci. 87:269-275.

Williams, S. R. O., P. J. Moate, M. C. Hannah, B. E. Ribaux, W. J. Wales, and R. J. Eckard. 2011. Background matters with the $\mathrm{SF}_{6}$ tracer method for estimating enteric methane emissions from dairy cows: A critical evaluation of the $\mathrm{SF}_{6}$ procedure. Anim. Feed Sci. Technol. 170:265-276. 